\title{
High graphene fillers content for improving the tribological performance of silicon
} nitride-based ceramics

\author{
Javier Llorente, Cristina Ramírez, Manuel Belmonte* \\ Institute of Ceramics and Glass (ICV-CSIC), Campus Cantoblanco, Kelsen 5, 28049 \\ Madrid, Spain
}

\begin{abstract}
The aim of this work is to investigate the effect of large graphene nanoplatelets (GNPs) additions on the friction and wear of silicon nitride $\left(\mathrm{Si}_{3} \mathrm{~N}_{4}\right)$ ceramics using linear reciprocating ball-on-plate tests lubricated with isooctane. All $\mathrm{Si}_{3} \mathrm{~N}_{4} / \mathrm{GNPs}$ composites, with up to 20.6 vol. \% of graphene fillers, exhibit better tribological response than $\mathrm{Si}_{3} \mathrm{~N}_{4}$, in particular, a $50 \%$ reduction in the friction that continuously decreases with the GNPs content is attained, jointly with an improvement in the wear resistance of up to $63 \%$. The survival of a self-lubricant carbon-rich tribolayer formed on the worn surfaces controls the tribological properties of the materials. These results are very promising to further explore the use of $\mathrm{Si}_{3} \mathrm{~N}_{4} / \mathrm{GNPs}$ composites in high pressure gasoline direct injection systems.
\end{abstract}

Keywords: Ceramic-matrix composite; Graphene; Sliding friction; Sliding wear; Wear testing

\section{Introduction}

The lubricating and wear-protecting properties of graphene have been extensively investigated in the last ten years using a great variety of testing conditions, from the nano- to the macro-scale [1-2]. The outstanding tribological results observed when graphene is employed as solid lubricant (added to a liquid medium or deposited onto a surface), motivated the addition of this material as filler into polymeric, metallic and ceramic matrices to enhance their tribological performances. At present, these graphenebased composites have shown, in general, very promising tribological results [3]. In the case of ceramic/graphene composites, the addition of graphene fillers, typically

*Corresponding author. Phone: +34-917355863; Fax: +34-917355843. E-mail: mbelmonte@icv.csic.es (M. Belmonte) 
graphene nanoplatelets (GNPs), has led to friction decreases of 7-70\% and wear resistances that scanned enhancements from 50 to $95 \%$ [4]. These results mainly depend on the ceramic material, the filler content and the testing conditions. It is also noticeable that in most of those works the composites contained graphene amounts below 10 vol.\% [4], predominantly $\leq 5 \mathrm{vol} . \%$, and today the direct effect of the graphene content on the tribological properties remains unclear.

At the moment, there are just few studies analysing the friction and wear performance of ceramic composites with large graphene contents [5-9], which present distinct results. In the case of silicon nitride $\left(\mathrm{Si}_{3} \mathrm{~N}_{4}\right) / \mathrm{GNPs}$ composites, Rutkowski et al. [5] reported better tribological results under dry sliding conditions for very low GNPs additions (0.71.5 vol.\%), despite maximum GNPs contents of $\leq 11.4$ vol.\% were used. On the other hand, Balazsi et al. [7] found a continuous decrease in the wear volume and a more stable frictional behaviour under water lubrication of $\mathrm{Si}_{3} \mathrm{~N}_{4} /$ multilayered graphene $(0$ $14.7 \mathrm{vol} . \%$ ) composites as the graphene content increased, due to the development of a well adhered lubricating tribofilm. The tribological response of yttria-stabilized tetragonal zirconia (3YTZP)/(0-10 vol.\%) GNPs composites under dry testing conditions was investigated by Gutierrez et al. [9]. These authors concluded that, despite all composites exhibited improved tribological properties than 3YTZP, 2.5 vol.\% GNPs arose as the key content because larger amounts had a detrimental effect on friction and wear due to the decrease in the hardness and the augment of GNPs agglomerates, respectively. Finally, some of the present authors analysed the tribological response of SiC/GNPs composites with graphene contents up to $20 \mathrm{vol} \%$ in dry [6] and isooctane-lubricated [8] sliding tests. Under dry sliding, the friction in the running-in-period and the wear volume continuously decreased with the fillers content; whereas under isooctane lubricating conditions, the friction considerably diminished just for $\mathrm{SiC} / 20$ vol.\% GNPs composite and the wear resistance for this material improved only at low loads due to the negative role played by its worse mechanical properties. These studies evidenced the complexity to predict a direct relationship of the tribological properties with the GNPs content, which depended, on one hand, on the ability of the graphene fillers to be pulled-out and exfoliated, creating a stable wear protecting and lubricating graphene-based tribofilm and, on the other hand, on the effect of the GNPs addition on the mechanical properties. 
Therefore, and taking into account the above issues, it would be remarkable to deepen into the tribological study of ceramic-based composites with high graphene additions, as is of great interest considering the extraordinary benefits that could give to practical applications, such as in the automotive industry. In this particular case, the design of more efficient gasoline direct injection (GDI) engines highly demands the development of more wear resistant components able to reduce the friction as well [10]. In this sense, $\mathrm{Si}_{3} \mathrm{~N}_{4}$ composites are excellent candidates to fulfil those requirements and, in fact, $\mathrm{Si}_{3} \mathrm{~N}_{4}$ containing carbon nanotubes exhibited improved friction and wear resistance behaviour under isooctane lubrication using a reciprocating ball-on-plate configuration that tried to simulate certain GDI conditions [11], and an enhanced mechanical efficiency in a highpressure 3-piston prototype pump for gasoline using a cam/pusher system [12]. Based on those studies, the aim of this work is to evaluate the effect of high GNPs contents (up to 20.6 vol. \%) in the tribological properties of isooctane lubricated $\mathrm{Si}_{3} \mathrm{~N}_{4}$-based ceramics and, hence, its potential use for GDI engines, deeply analysing with different techniques the role played by graphene on the friction and wear mechanisms.

\section{Materials and methods}

\subsection{Materials fabrication}

A reference $\mathrm{Si}_{3} \mathrm{~N}_{4}$ material ("SN") and four $\mathrm{Si}_{3} \mathrm{~N}_{4} / \mathrm{GNPs}$ composites containing 4.4 (“SN4GNP”), 11.3 (“SN11GNP”), 14.0 (“SN14GNP”) and 20.6 vol.\% (“SN20GNP”) of graphene fillers (type N002, Angstron Materials Inc.) were manufactured [13-14]. The ceramic matrix was produced by attrition milling in isopropyl alcohol $93 \mathrm{wt} . \%$ of $\mathrm{Si}_{3} \mathrm{~N}_{4}$ powders (SN-E10, UBE Industries), 2 wt.\% of $\mathrm{Al}_{2} \mathrm{O}_{3}$ (SM8, Baikowski Chimie) and $5 \mathrm{wt} . \%$ of $\mathrm{Y}_{2} \mathrm{O}_{3}$ (Grade C, H.C. Starck). This ceramic slurry was mixed with a previously sonicated isopropyl alcohol suspension containing the final GNPs amounts for each ceramic/graphene batch. After solvent removal, the composite powders were dried and sieved.

Disc specimens of $20 \mathrm{~mm}$ diameter x $3 \mathrm{~mm}$ height were spark plasma sintered (SPS, SPS-510CE, Fuji Electronic Industrial Co., Ltd.) at $1625^{\circ} \mathrm{C}$ for 5 min under vacuum atmosphere $(6 \mathrm{~Pa})$, applying an uniaxial pressure of $50 \mathrm{MPa}$ during the heating ramp. The materials presented densification above $99 \%$ of the theoretical value, $10-23 \%$ of $\alpha$ $\mathrm{Si}_{3} \mathrm{~N}_{4}$ phase content, mean grain size of 0.4-0.7 $\mu \mathrm{m}$ and aspect ratio of 1.8-2.2. As reported in previous works, the GNPs dispersion within the ceramic matrix is uniform 
[13]. Besides, GNPs appear preferentially oriented with their basal plane perpendicular to the SPS pressing axis [13], which causes anisotropy in the properties of these kind of composites [4].

\subsection{Mechanical and tribological characterization}

The specimens were polished using a conventional ceramographic polishing procedure up to $1 \mu \mathrm{m}$ diamond paste. The topography of the as-polished samples was studied with a contact profilometer (Dektak XT, Bruker) to evaluate the following roughness parameters: $\mathrm{R}_{\mathrm{a}}, \mathrm{R}_{\mathrm{Z}}$, and $\mathrm{R}_{\mathrm{v}}$ as defined in ISO4287 [15].

Hardness (H) and elastic modulus (E) were measured by depth-sensing Vickers indentation (Zwick-Roell, Zwick 2.5 Model) using a load of $49 \mathrm{~N}$ on the plane perpendicular to the SPS furnace axis. The estimation of E was carried-out using the Oliver-Pharr method [16] in the unloading branch and applying the correction due to the frame compliance of the indenter. At least five valid indentations were carried out per composition, and data here represent their average.

Before tribological tests, specimens were ultrasonically cleaned ( 2 min in acetone plus 2 min in ethanol). Linear-reciprocating ball-on-plate tests were performed using a commercial tribometer (UMT3, CETR) at loads $\left(F_{N}\right)$ of 50, 100 and $180 \mathrm{~N}$ under lubrication with isooctane (Merck \& Co. Inc) in full-immersion condition. This lubricant was chosen as substitute of gasoline because presents similar properties than gasoline (viscosity $=0.5 \mathrm{mPa} \cdot \mathrm{s}$ at $20^{\circ} \mathrm{C}$ ) but its less explosive, making safer the laboratory tests. The plates were the manufactured discs and the balls were commercial $\mathrm{Si}_{3} \mathrm{~N}_{4}$ spheres (10.3 mm diameter, SN101C, Saint Gobain). The tests were carried out on the specimen surface perpendicular to the SPS furnace axis, i.e., in the plane where the GNPs are preferentially aligned (see graphical scheme in [8]). The amplitude and frequency were $2.5 \mathrm{~mm}$ and $20 \mathrm{~Hz}$, respectively, that corresponded to a sliding speed of $0.1 \mathrm{~ms}^{-1}$. The total sliding distance $(l)$ was $360 \mathrm{~m}$. These testing parameters, including the counterbody, were selected based on some previous works (see [8] as an example), to better focus on the role played by GNPs on this tribosystem, but also looking for potential applications under highly demanding conditions in the automotive industry. Stribeck tests were also conducted under the same testing conditions (after a running-in period of $180 \mathrm{~m}$ at $20 \mathrm{~Hz}$ ) varying the reciprocating frequency between 0.5 and $40 \mathrm{~Hz}$ (time permanence of 2 min en each step). 
The friction coefficient, $\mu$, was in situ recorded during the sliding experiments and, afterwards, the steady-state friction coefficient $\left(\mu_{\mathrm{ss}}\right)$ was assessed within the 200-360 m interval. A stylus profilometer (Dektak XT, Bruker) was used to determine the width $(d)$ and depth $\left(W_{l}\right)$ of the scars as well as the cross section area beneath the $2 \mathrm{D}$ curves $(A)$. Known the amplitude $(\Delta x)$, the wear volume of the plates $\left(\mathrm{W}_{\mathrm{V}}\right)$ and the wear rate $\left(\mathrm{W}_{\mathrm{R}}\right)$ were calculated employing these expressions:

$$
\begin{aligned}
& \mathrm{W}_{\mathrm{V}}=\Delta \mathrm{x} \cdot \mathrm{A}+\pi \cdot \frac{\mathrm{d}^{2}}{8} \cdot \mathrm{W}_{\mathrm{l}} \\
& W_{R}=\frac{W_{V}}{F_{N} \cdot l}
\end{aligned}
$$

Data correspond to the average value of a minimum of three consistent tests.

Wear scars were analysed by scanning electron microscopy (SEM, TM1000 and S-4700 models, Hitachi) and micro-Raman spectroscopy (Alpha3000 WITec GmbH), in this case using the $532 \mathrm{~nm}$ laser wavelength excitation on scanned maps of $50 \times 50 \mu \mathrm{m}^{2}(25$ x 25 pixels) as well as in-depth profiles (5 $\mu \mathrm{m}$ depth). Focused-ion-beam SEM (FIBSEM, Helios Nanolab 600) and energy dispersive X-ray spectroscopy (EDS) were employed to in situ observe and analyse the worn surface and the sub-surface damage in the wear tracks.

\section{Results and discussion}

In order to know the lubrication regime working in the present tribosystems, preliminary Stribeck tests were conducted in the reference material (SN) and the ceramic/graphene composites with the lowest and highest GNPs contents (SN4GNP and SN20GNP). Figure 1 shows that in all cases the tribosystem worked in the mixed lubrication regime, which means that the direct contact between the surfaces of both counterbodies (ball and plate) is not fully broken by a fluid film, as it typically happens in the hydrodynamic regime. Therefore, the mixed lubrication regime would allow investigating the wear and friction phenomena directly related to the properties of the materials in close contact. From the curves of Figure 1, it can be observed that the highest $\mu$ values were attained for SN; whereas SN20GNP exhibited an outstanding decrease in this parameter, highlighting the beneficial effect of large GNPs amounts on the friction behaviour of these tribosystems, especially at high loads. The arrows in the plots point to the conditions employed in the subsequent tribological tests. 
Figure 2 collects the friction results of the test carried out at the fixed reciprocating frequency of $20 \mathrm{~Hz}$ using different loads. At a first glance, all composites exhibited an important decrease of friction in comparison with the monolithic ceramics. In addition, SN presented at the very beginning of the tests a much higher $\mu$ value than the composites (Fig. 2a-c). It should be noted that, although all materials were polished using the same procedure, the surface finishing was not exactly the same. Actually, $R_{a}$ increased from $2 \pm 0.8 \mathrm{~nm}(\mathrm{SN})$ to $13 \pm 2 \mathrm{~nm}(\mathrm{SN} 20 \mathrm{GNP})$, as well as $\mathrm{R}_{\mathrm{Z}}(11 \pm 3 \mathrm{~nm}$ for $\mathrm{SN}$ and $150 \pm 2 \mathrm{~nm}$ for SN20GNP). This augment in the surface roughness was mainly associated to the increase in the $\mathrm{R}_{\mathrm{v}}$ parameter (maximum depth of the valleys) with the GNPs content, ranging from $6 \pm 2 \mathrm{~nm}(\mathrm{SN})$ to $80 \pm 30 \mathrm{~nm}$ (SN20GNP), which would be linked to the pull-out of the nanoplatelets during the polishing process. This fact would promote a smaller contact area in the composites than in the reference material, limiting the friction at the first instants of the tests. Once the semi-steady state was achieved typically after around $40 \mathrm{~m}-$, the effect of the initial surface roughness vanished.

a)

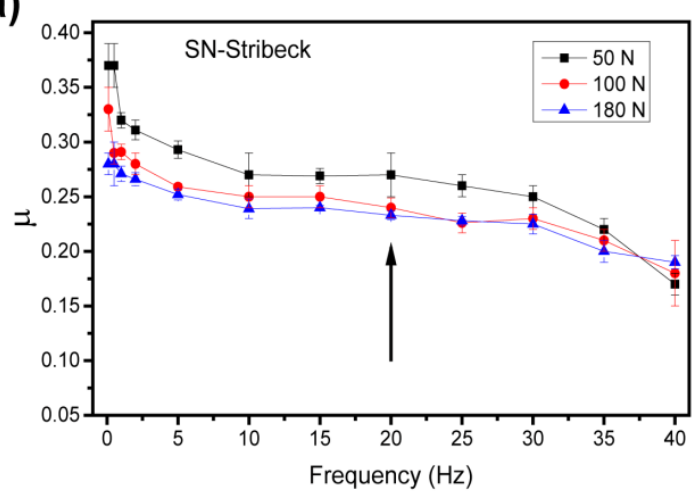

b)

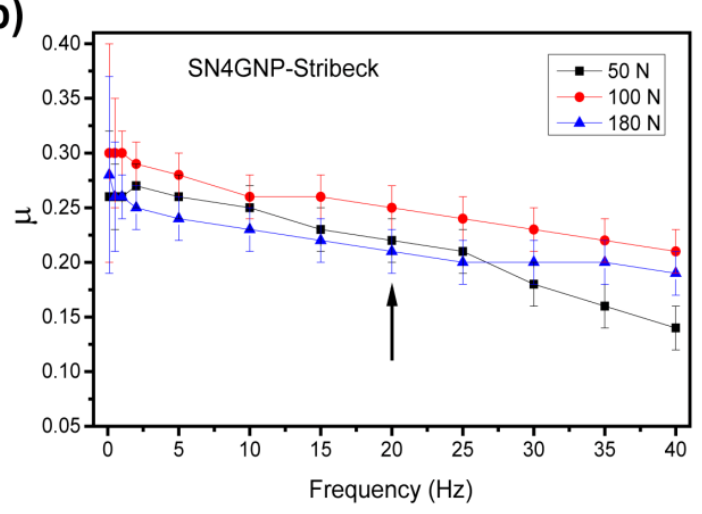

c)

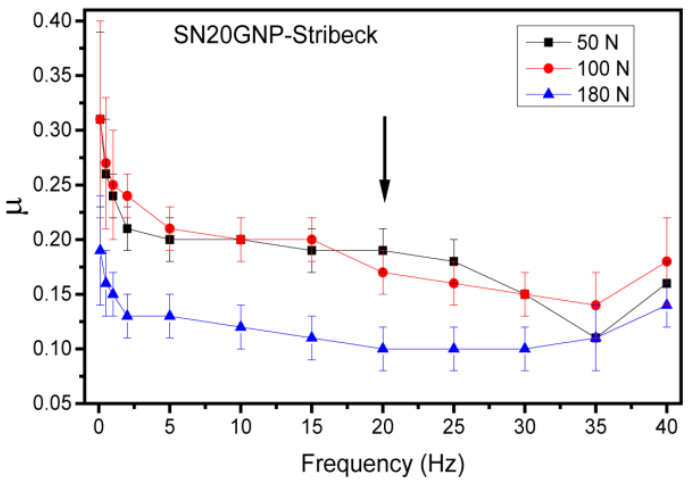

Figure 1. Stribeck tests for: a) SN, b) SN4GNP and c) SN20GNP specimens. The arrows point to the conditions employed in the subsequent tribological tests. 
The $\mu_{\mathrm{ss}}$ evolution with the GNPs content and the load is shown in Figure 2d. At intermediate and high loads, the composite with the largest GNPs content (SN20GNP) led to the maximum reductions in $\mu_{\mathrm{ss}}(46 \%$ and $52 \%$ for $100 \mathrm{~N}$ and $180 \mathrm{~N}$, respectively). In addition, it seems that this tribological parameter continuously decreased with the amount of fillers. At low loads $(50 \mathrm{~N})$, the largest decrease in $\mu_{\mathrm{ss}}$ (54\%) was attained for SN14GNP composite, closely followed by SN20GNP (43\%), and the tendency of $\mu_{\mathrm{ss}}$ with the GNPs content was not constant. Moreover, the friction curves of the composites seems to be much more unstable than those for the reference material, instability that strongly decreased with the load (Fig. 2a-c), which could be related to dynamic processes in the tribocontact associated at the tribolayer evolution.

The friction reduction achieved in the present work $(\sim 50 \%$, independently of the load) is slightly higher than that reported for most of ceramic/graphene tribosystems, which typically are below 40\% [4]. Interestingly, SiC/GNPs composites tested under identical conditions [8] to the present work, and also containing large amounts of fillers (up to 20 vol.\%), showed a distinct friction behaviour. In this way, a maximum reduction of about $30 \%$ for all loads was attained for SiC20GNP, but for lower GNPs contents the effect in friction was negligible. This can be explained because $\mathrm{SiC}$ ceramics commonly show lower friction coefficients than $\mathrm{Si}_{3} \mathrm{~N}_{4}$ ones and, hence, larger filler contents are necessary to achieve a clear improvement in the friction response of $\mathrm{SiC}$ [8].
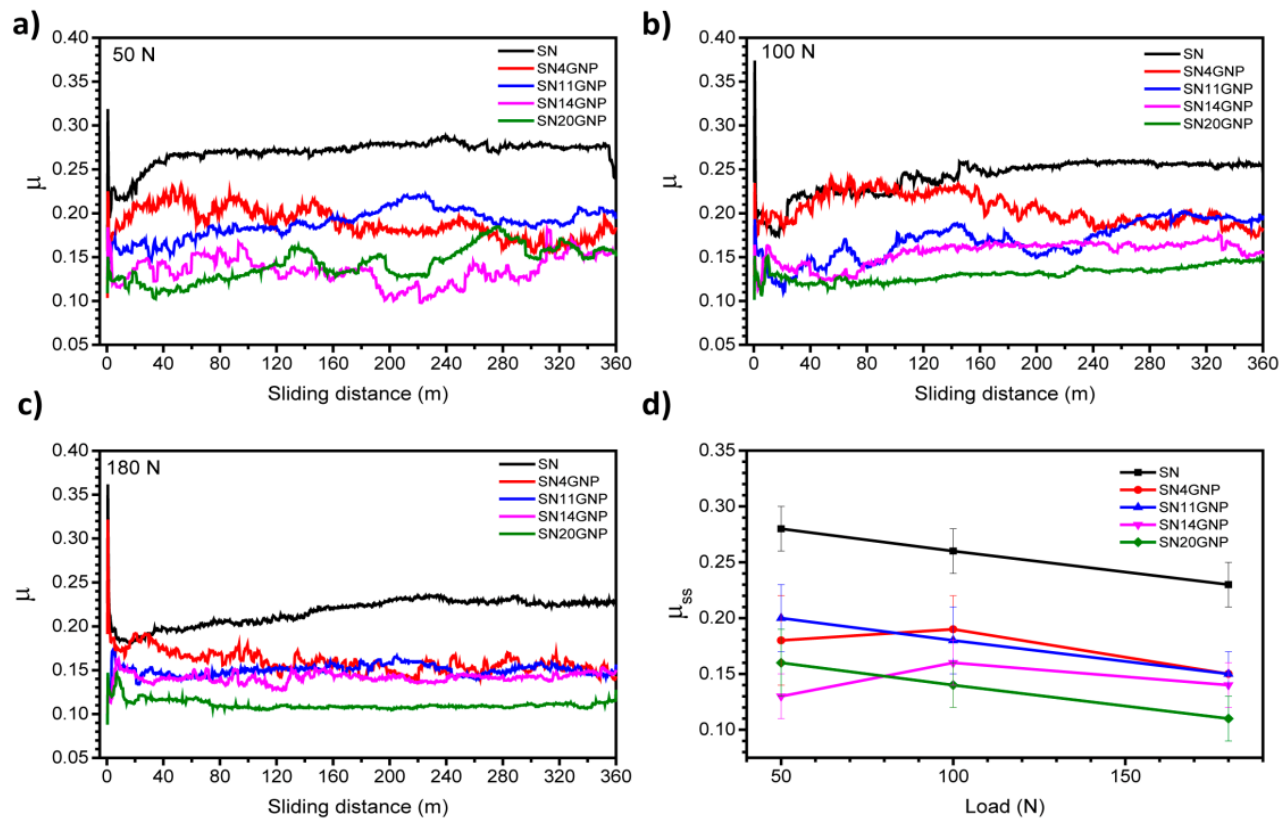

d)

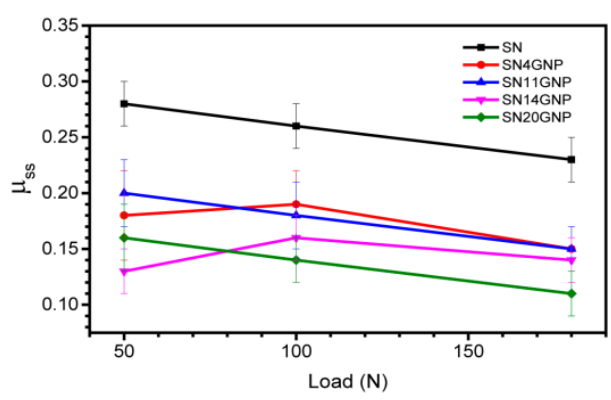


Figure 2. Friction coefficient $(\mu)$ evolution at $50 \mathrm{~N}(\mathrm{a}), 100 \mathrm{~N}(\mathrm{~b})$ and $180 \mathrm{~N}$ (c) of the reference material and composites. d) Steady-state friction coefficient $\left(\mu_{\mathrm{ss}}\right)$ versus the load. (For interpretation of the references to colour in this figure legend, the reader is referred to the web version of this article).

Regarding the wear behaviour, all GNPs composites exhibited higher wear resistance than the reference material for all tested loads (Figure 3a), although the trend followed by the composites varied with the load. In this way, at $50 \mathrm{~N}, \mathrm{~W}_{\mathrm{V}}$ continuously diminished with the amount of GNPs, reaching improved resistances that ranged from $48 \%$ (SN4GNP) up to 63\% (SN20GNP) as compared to SN. However, at $100 \mathrm{~N}$, the wear volume of SN4GNP almost kept constant but increased for the rest of composites. As a result, SN4GNP became more wear resistant than SN20GNP. Finally, at 180 N, most of composites showed a slight $\mathrm{W}_{\mathrm{V}}$ increment, except for SN20GNP that it was more pronounced. At this load, the most wear resistant was again SN4GNP (53\% higher than SN), followed by the rest of composites in decreasing order by GNPs content (35, 24 and 3\% for composites containing 11, 14 and 20 vol.\% GNPs). In terms of wear rate, all materials presented values in the order of $10^{-8} \mathrm{~mm}^{3} \cdot \mathrm{N}^{-1} \cdot \mathrm{m}^{-1}$ (Figure $3 \mathrm{~b}$ ), the composites having values in the $2.0-5.0 \times 10^{-8} \mathrm{~mm}^{3} \cdot \mathrm{N}^{-1} \cdot \mathrm{m}^{-1}$ range, that would correspond to a mild wear regime.
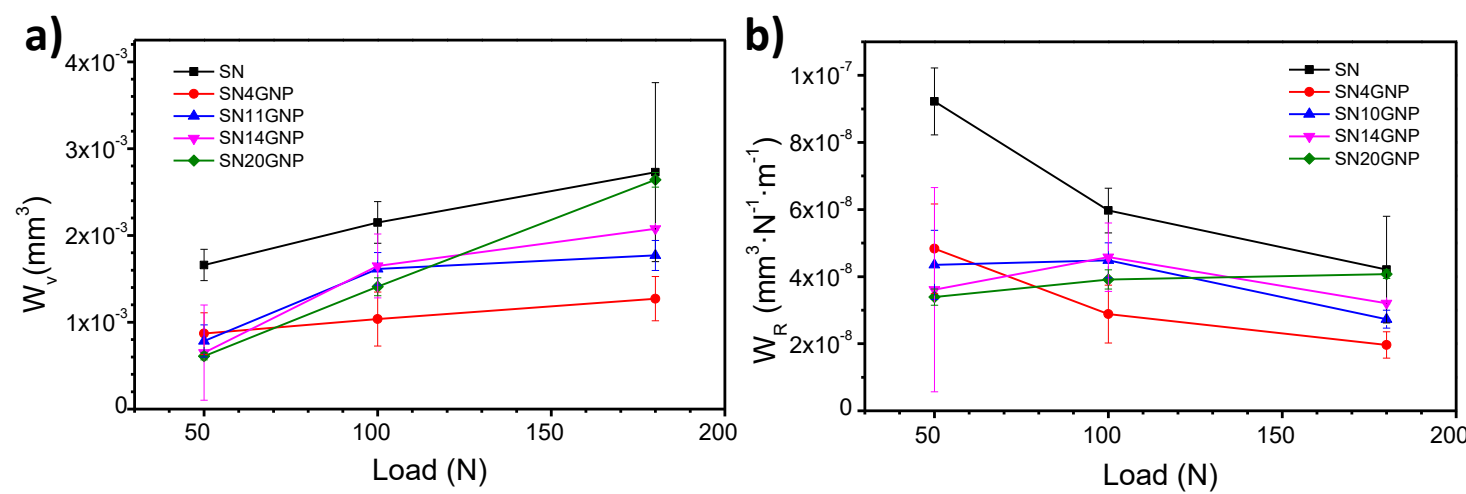

Figure 3. a) Wear volume $\left(\mathrm{W}_{\mathrm{v}}\right)$ and b) wear rate $\left(\mathrm{W}_{\mathrm{R}}\right)$ of the plates for the different tested materials and loads.

In order to elucidate the mechanisms that take place during the tribological process, as well as the role played by the increasing amounts of GNPs in the friction and wear, the worn surfaces were analysed by different techniques. In terms of friction, there is a general consensus that relates the better friction performance of ceramic/graphene 
composites with the formation of a lubricant carbon-rich tribofilm [4]. In the current case, the presence of this tribolayer was also confirmed, even by optical microscopy $(\mathrm{OM})$, as Figure 4 depicts with some examples taken from wear tracks tested at $50 \mathrm{~N}$ in different materials. In this sense, SN showed on the worn surface brown-coloured zones that would be related to a transfer film due to the lubricant (isooctane); while all composite tracks presented those zones and, additionally, blue-coloured areas that could be associated to a carbon-rich tribolayer, although this fact must be explored in depth.

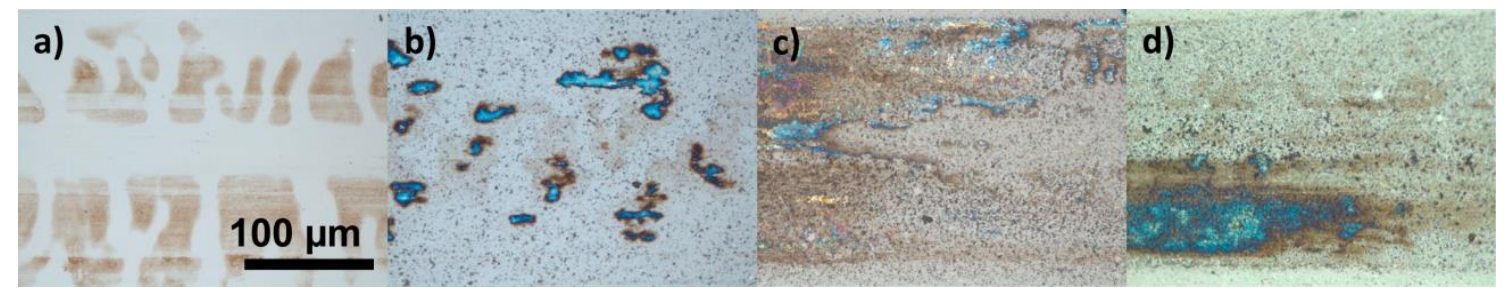

Figure 4. OM of the wear tracks at $50 \mathrm{~N}$ for: a) SN, b) SN4GNP, c) SN11GNP and d) SN20GNP materials.

In this way, FIB-SEM was performed on the SN11GNP wear track to create an in-situmilled trench at the tribolayer (Figure 5a). A close observation of this trench clearly showed that the tribolayer was apparently formed by two different films (Figure 5b,c): i) a dense one on the specimen surface (Tribofilm A), with a thickness that varied from $\sim 20$ to $280 \mathrm{~nm}$ along the wear track, and ii) an outer thicker and less compacted film (Tribofilm B, $\sim 300-320 \mathrm{~nm}$ ) on the previous one. The chemical composition of both films could not be differentiated using EDS analysis, but undoubtedly they contained more carbon and oxygen than the untested material (Fig. 5d). The carbon would predominantly come from GNPs but also from the isooctane; whereas the oxygen would reflect the oxidation of the $\mathrm{Si}_{3} \mathrm{~N}_{4}$ debris during the sliding motion. The nature of this oxidation could be explained as reaction of the naturally formed $\mathrm{SiO}_{2}$ on $\mathrm{Si}_{3} \mathrm{~N}_{4}$ surfaces in air with water (ambient or solubilized in isooctane) to produce silicic acid $\left(\mathrm{H}_{4} \mathrm{SiO}_{4}\right)$. A profuse explanation of this mechanism in a similar system $(\mathrm{SiC}-\mathrm{SiC}$ tribopairs in isooctane) has been recently reported by Schreiber et al. [17]. 

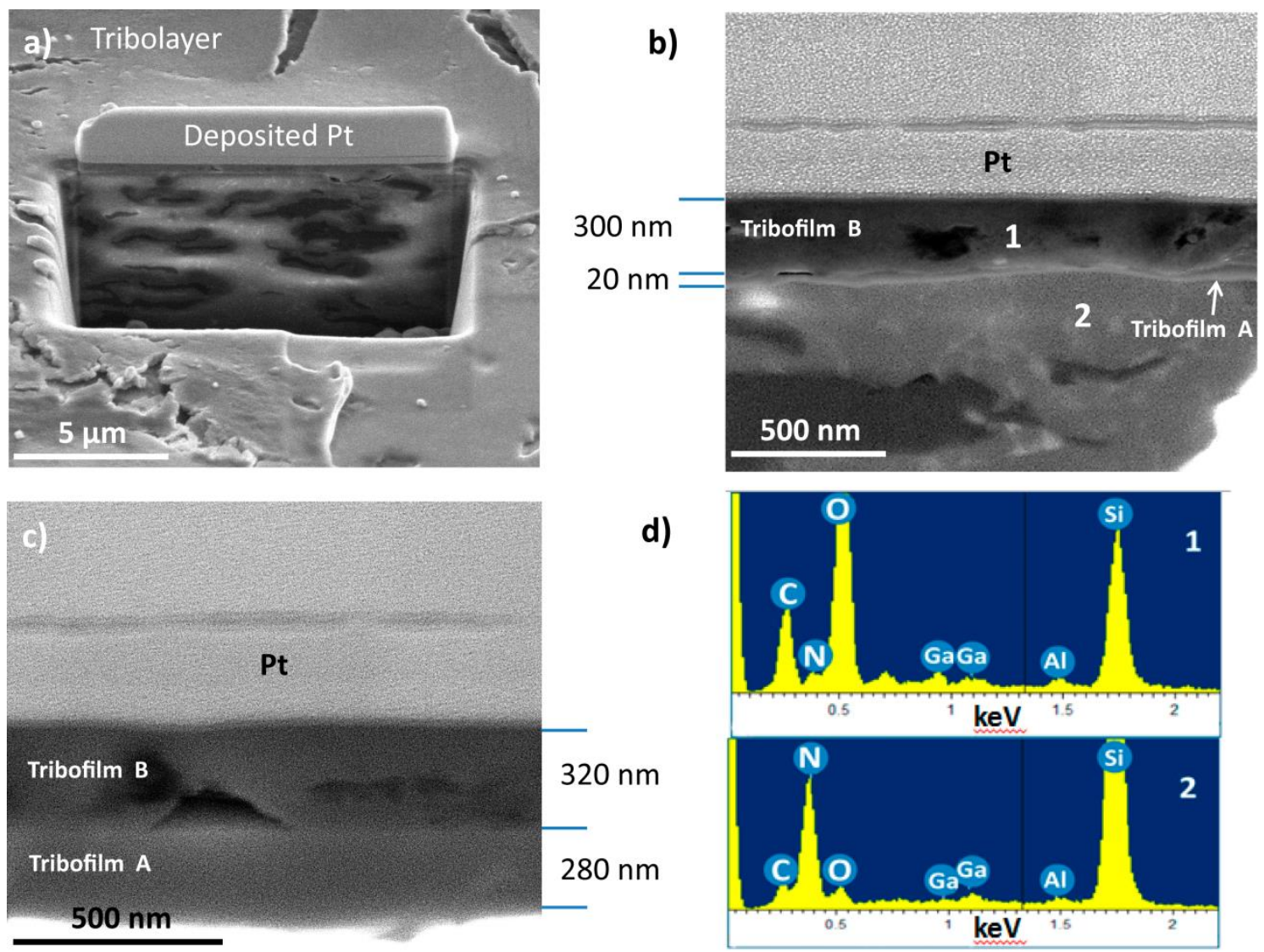

d)
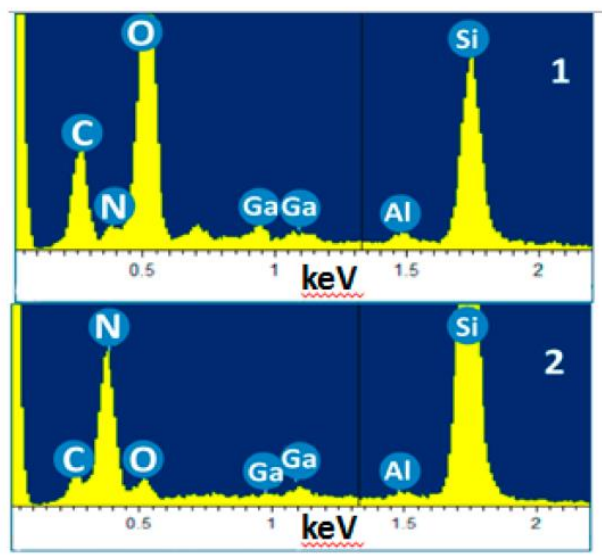

Figure 5. FIB-SEM analysis of the tribolayer formed on the SN11GNP composite tested at 100 N. SEM micrographs of: a) in situ-milled trench; b) and c) tribolayer in two different zones of the same wear track. d) EDS spectra taken in position 1 and 2 in b).

Joining the OM observations (Fig. 4) and FIB-SEM findings (Fig. 5), it would be possible to conclude that the brown-coloured areas in Fig. 4 would correspond to the inner film onto the specimen (Tribofilm A, Fig. 5b,c), a transfer-film mostly formed by the lubricant (isooctane) and oxidised ultrafine $\mathrm{Si}_{3} \mathrm{~N}_{4}$ debris, while the blue-coloured zones (Fig. 4) would be related to the outer film (Tribofilm B, Fig. 5b,c), a surface tribolayer mostly created from the mixture of oxidised $\mathrm{Si}_{3} \mathrm{~N}_{4}$ particles and GNPs detached from the matrix and mechanically crushed at the tribocontact.

Micro-Raman spectroscopy was employed to shed some light on the outer tribofilm formation and composition (Figure 6). The average Raman spectrum of the untested SN20GNP composite material clearly showed the main bands corresponding to GNPs (D, G and 2D bands) and $\mathrm{Si}_{3} \mathrm{~N}_{4}$ (Fig. 6a). These bands appeared in all composites. Merging the G-band and the most intense $\mathrm{Si}_{3} \mathrm{~N}_{4}$ band $\left(\sim 203 \mathrm{~cm}^{-1}\right)$, false coloured Raman images were created for SN4GNP and SN20GNP debris (Fig. 6b), where blue 
and green colours corresponded to GNPs and $\mathrm{Si}_{3} \mathrm{~N}_{4}$, respectively. As expected, the areas coloured in blue (GNPs) in the untested composites are larger for SN20GNP than for SN4GNP. The evolution with the load evidenced that while the blue area associated to GNPs slightly augmented for SN4GNP, in the case of SN20GNP the wear track was progressively coated by debris linked to GNPs. Therefore, the results would indicate that the decrease in the friction with the filler content (Fig. 2) would be related to the gradual formation of a adhered carbon-rich tribofilm, GNPs already acting as selflubricant in the tribosystem. Moreover, the intensity ratio between D and G bands $\left(\mathrm{I}_{\mathrm{D}} / \mathrm{I}_{\mathrm{G}}\right)$ in the worn surfaces -which would give an idea about the damage of the graphene structures, being more defective as $\mathrm{I}_{\mathrm{D}} / \mathrm{I}_{\mathrm{G}}$ increases- were also assessed (Fig. 6c). As expected, the mechanical stresses reached at the tribocontact during the sliding motion induced the progressive damage of GNPs on the tested surface with the load. That damage augmented much faster for composites with high GNPs amounts (SN20GNP), as larger number of nanoplatelets would be pulled-out from the tested surface and, afterwards, crushed to form the carbonaceous tribofilm. It seems that the maximum $\mathrm{I}_{\mathrm{D}} / \mathrm{I}_{\mathrm{G}}$ of the GNPs forming the tribofilm is around 0.8 , value that was not attained for SN4GNP even at $180 \mathrm{~N}$. 
a)
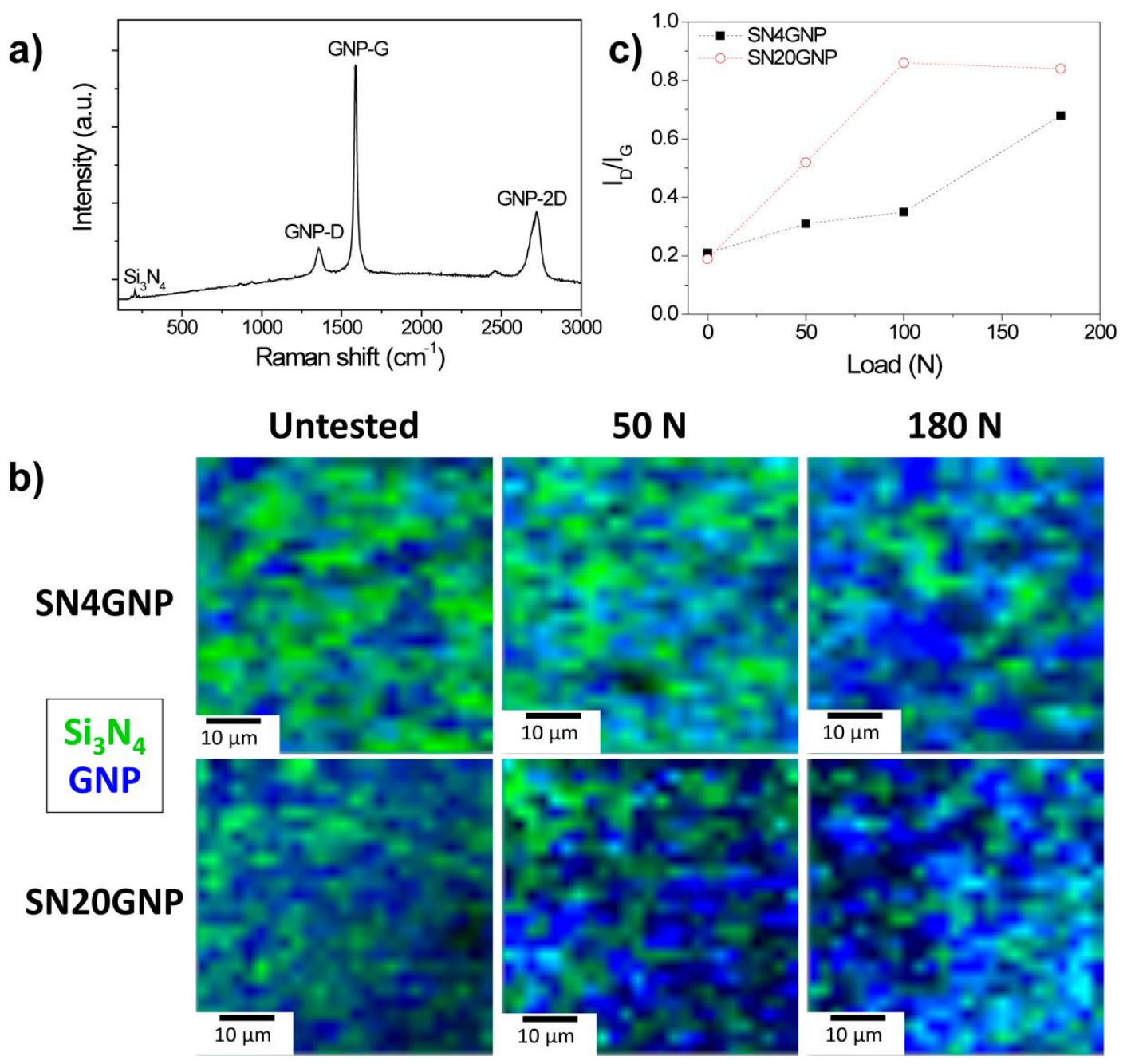

\section{$50 \mathrm{~N}$}

$180 \mathrm{~N}$

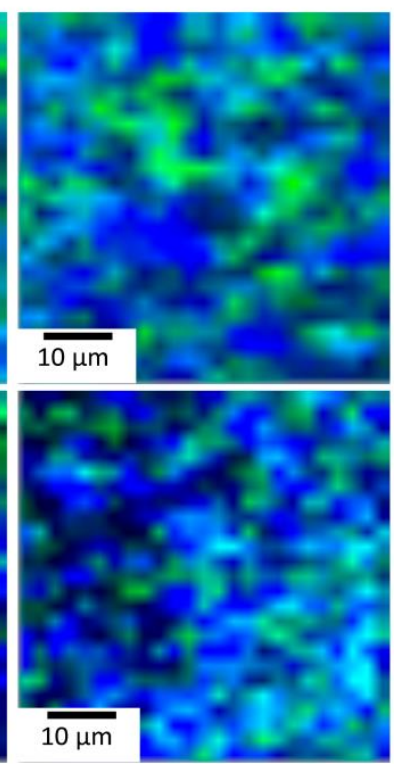

Figure 6. a) Average Raman spectrum of untested SN20GNP composite. b) False coloured Raman images of SN4GNP and SN20GNP composites for untested and $50 \mathrm{~N}$ and $180 \mathrm{~N}$ tested surfaces. Blue and green colours correspond to GNPs and $\mathrm{Si}_{3} \mathrm{~N}_{4}$ debris, respectively. c) $\mathrm{I}_{\mathrm{D}} / \mathrm{I}_{\mathrm{G}}$ evolution of the scanned maps recorded on the wear tracks as a function of the load for SN4GNP and SN20GNP composites. All the maps were fitted to the same scale of intensities.

To complete this Raman study, some of the tribofilms observed in the OM images of SN4GNP and SN20GNP (blue areas in Fig. 4) were also in-depth Raman analysed along the $\mathrm{Z}$ axis (Figure 7). The combination of the false coloured Raman images merging $D$ and $G$ bands- and the individual spectra taken in position 1 confirmed the formation of a carbon-rich tribofilm on the tested surfaces, which is highly defective. The Raman signal relative to $\mathrm{Si}_{3} \mathrm{~N}_{4}$ particles is mostly hindered by the intense signal of carbonaceous bands and the strong fluorescence of the tribofilm and, hence, it was only 
detectable below this film, as pointed the insets in the Raman spectra at position 2. The thickness of the whole tribolayer was roughly estimated, being $\sim 1 \mu \mathrm{m}$ and $\sim 2 \mu \mathrm{m}$ for SN4GNP and SN20GNP, respectively. These values were thicker than that measured by FIB-SEM -up to $600 \mathrm{~nm}$ (Fig. 5)- and could be overestimated considering that the spatial resolution of the Raman technique is $\sim 1 \mu \mathrm{m}$. Nevertheless, there is clear evidence of the relationship between the GNPs content and the development of a lubricating layer, becoming thicker as the amount of GNPs increases.
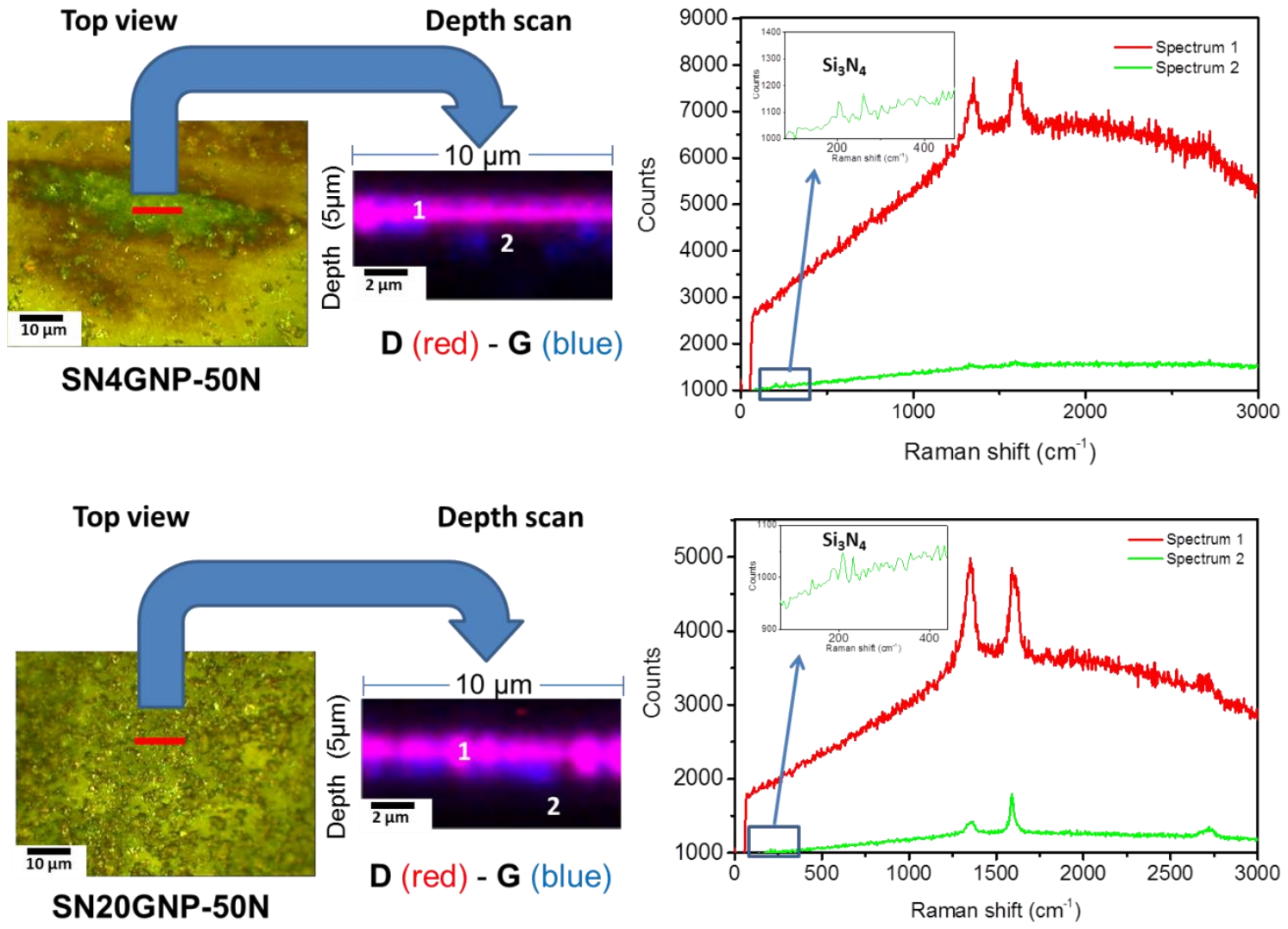

Figure 7. Optical micrographs of selected worn zones and in-depth micro-Raman analysis of tribofilms in SN4GNP and SN20GNP composites tested at $50 \mathrm{~N}$. The single spectrum in position 1 and 2 are also plotted and insets show a magnification of the $\mathrm{Si}_{3} \mathrm{~N}_{4}$ Raman bands.

In terms of wear behaviour, a similar initial effect was observed in SiC/GNPs composites tested under the same conditions [8], i.e., the most wear resistant material at $50 \mathrm{~N}$ was the composite with the largest GNPs content (20 vol.\%) due to the formation of a carbon-based protecting tribolayer. However, for higher loads the situation was reverted, the tribolayer effect vanished and the $\mathrm{SiC}$ reference material exhibited better 
resistance than all composites due to the worsening of the hardness $(\mathrm{H})$ and elastic modulus (E) with the GNPs additions. Actually, a linear dependence of $\mathrm{W}_{\mathrm{R}}$ with those mechanical parameters was found [8] using Hsu and Shen's expression for ceramics having a mild wear response [18]. In the present case, a comparable exercise was done, but despite $\mathrm{H}$ and $\mathrm{E}$ of $\mathrm{Si}_{3} \mathrm{~N}_{4}$ materials diminished with the addition of GNPs (Figure 8a), a clear dependence between $\mathrm{W}_{\mathrm{R}}$ and $\mathrm{H}$ and $\mathrm{E}$ was only established for composites tested at $180 \mathrm{~N}$ (Figure $8 \mathrm{~b}$ ). In fact, experimental data at that load linearly fitted $\left(\mathrm{R}^{2} \sim\right.$ 0.986) to the predicted values for materials having a carbonaceous tribolayer on the worn surface, i.e., composites. That tribolayer seems to compensate the negative impact of the mechanical properties in the wear resistance at 50 and $100 \mathrm{~N}$, but its destabilization at the highest load minimized that effect. This response differs from that of $\mathrm{SiC} / \mathrm{GNPs}$ composites because the decrease in $\mathrm{E}$ and $\mathrm{H}$ for $\mathrm{Si}_{3} \mathrm{~N}_{4} / \mathrm{GNPs}$ (up to $\sim 50 \%$, Fig. 8a) is less pronounced than for SiC/GNPs (up to 70\%) [19] and, hence, the tribolayer created on $\mathrm{Si}_{3} \mathrm{~N}_{4}$ composites remained more stable with the load.

a)

\begin{tabular}{|c|c|c|}
\hline Material & $\begin{array}{c}\mathbf{E} \\
(\mathbf{G P a})\end{array}$ & $\begin{array}{c}\mathbf{H} \\
(\mathbf{G P a})\end{array}$ \\
\hline $\mathrm{SN}$ & $311 \pm 6$ & $16.9 \pm 0.3$ \\
\hline SN4GNP & $282 \pm 3$ & $15.5 \pm 0.1$ \\
\hline SN11GNP & $223 \pm 5$ & $11.4 \pm 0.4$ \\
\hline SN14GNP & $185 \pm 4$ & $10.8 \pm 0.4$ \\
\hline SN20GNP & $152 \pm 5$ & $8.7 \pm 0.4$ \\
\hline
\end{tabular}

b)

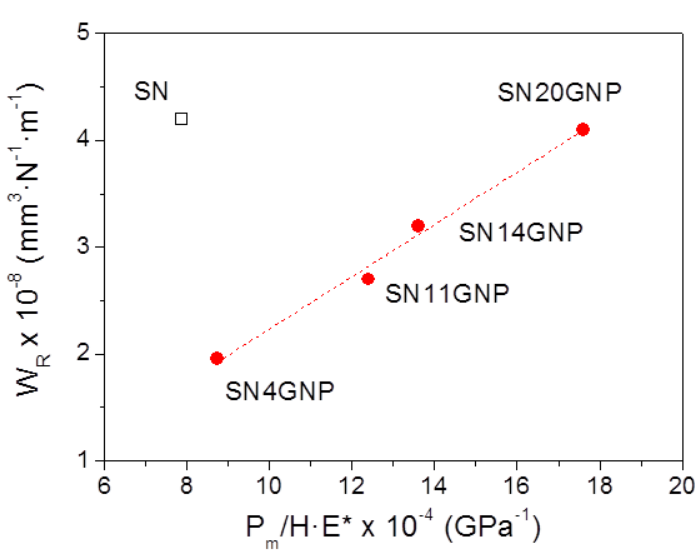

Figure 8. a) Table showing the elastic modulus (E) and hardness $(\mathrm{H})$ for the different materials and b) Wear rate $\left(\mathrm{W}_{\mathrm{R}}\right)$ versus $\mathrm{P}_{\mathrm{m}} / \mathrm{H} \cdot \mathrm{E}^{*}$ at $180 \mathrm{~N}$ following Hsu's model [19], where $\mathrm{P}_{\mathrm{m}}$ is the mean Hertzian pressure and $\mathrm{E}^{*}$ is the effective elastic modulus. There are other properties, such as the thermal conductivity, that could also influence the wear response of the materials by means of dissipating the local heat generated at the tribocontact, as some authors have appointed [20-21]. The in-plane thermal conductivity of $\mathrm{Si}_{3} \mathrm{~N}_{4}$, i.e., on the parallel surface to the tested surface, continuously increases with the addition of GNPs [22], in particular, up to $85 \%$ for composites containing 16.7 vol.\% GNPs as compared to the monolithic $\mathrm{Si}_{3} \mathrm{~N}_{4}$. Therefore, GNPs composites would favour faster heat dissipation at the tribocontact than $\mathrm{Si}_{3} \mathrm{~N}_{4}$ and, thus, 
the surface damage due to local thermal flashing effects would be minimized, improving the wear resistance.

At this stage, it is noticeable the relevance of the tribolayer in the tribological response of the tested materials, especially in the composites and, hence, a model describing the formation and stabilization of the tribolayer is proposed taking into account the characterization previously shown, as well as SEM observations of the worn surfaces (Figure 9).

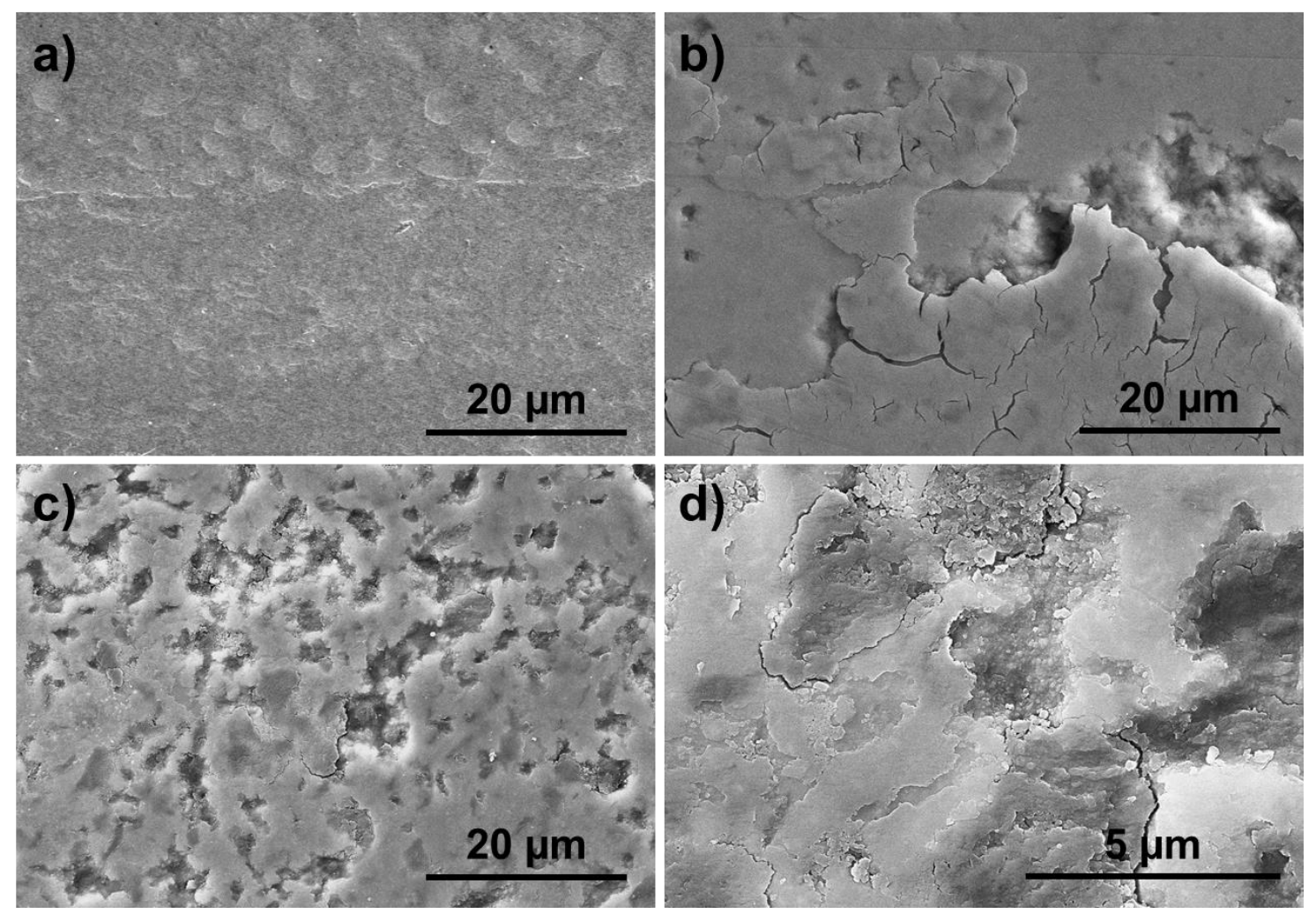

Figure 9. SEM micrographs of the tested surfaces at $180 \mathrm{~N}$ for: a) SN, b) SN4GNP, c) SN20GNPs and d) higher magnification of the tribolayer on the wear track of c).

The model (Figure 10) starts with the development of a thin transfer film formed by isooctane and ultrafine wear debris (Tribofilm A), which has been seen in all materials (Figs. 4 and 5) and testing conditions, and appeared as unique tribolayer in SN (Fig. 9a). However, this tribolayer is not enough to substantially reduce the friction and protect against wear (Figs. 2 and 3). In the case of composites, an additional thicker film (Tribofilm B) is built on the previous one (Fig. 5), leading to a final tribolayer that is formed by the sum of both tribofilms. This outer second film mainly comes from the pulling-out and crushing of GNPs, jointly with oxidised $\mathrm{Si}_{3} \mathrm{~N}_{4}$ particles, creating a self- 
lubricant carbonaceous tribofilm able to extraordinarily decrease the friction with the load and the GNPs content (Fig. 2). Besides, there are two important issues affecting the tribological response of the composites, in particular, the area of the wear tracks covered by the outer carbonaceous built-up tribofilm and its stabilization during the sliding tests. In this way, the increasing amount of GNPs promotes the formation of a larger, thicker and more uniform tribolayer, as seen in Figures 7 and 9b-d. Actually, and focusing on the two extreme GNPs compositions (4.4 and 20.6 vol.\%), SN4GNP track presents islands of tribolayer (Fig. 9b), while SN20GNP one is homogenously coated by this tribolayer (Fig. 9c,d). At low loads $(50 \mathrm{~N})$, that tribolayer seems to be stabilized and, thus, led to the maximum wear resistance. However, as the load increases, the mechanical stresses at the contact induce the cracking, destabilization and partial removal of the tribolayer, losing its wear protecting role. At this stage, the carbonaceous tribofilm would be continuously rebuilt using more material removed from the substrate, especially in composites with large GNPs amounts that present worse mechanical properties, which keeps low friction values but enhances the wear rate. Conversely, SN4GNP has a thinner and well adhered non-continuous tribofilm that almost remained invariable with the load, enough to reduce the friction as compared to $\mathrm{SN}$ and to maintain an excellent wear resistance performance.

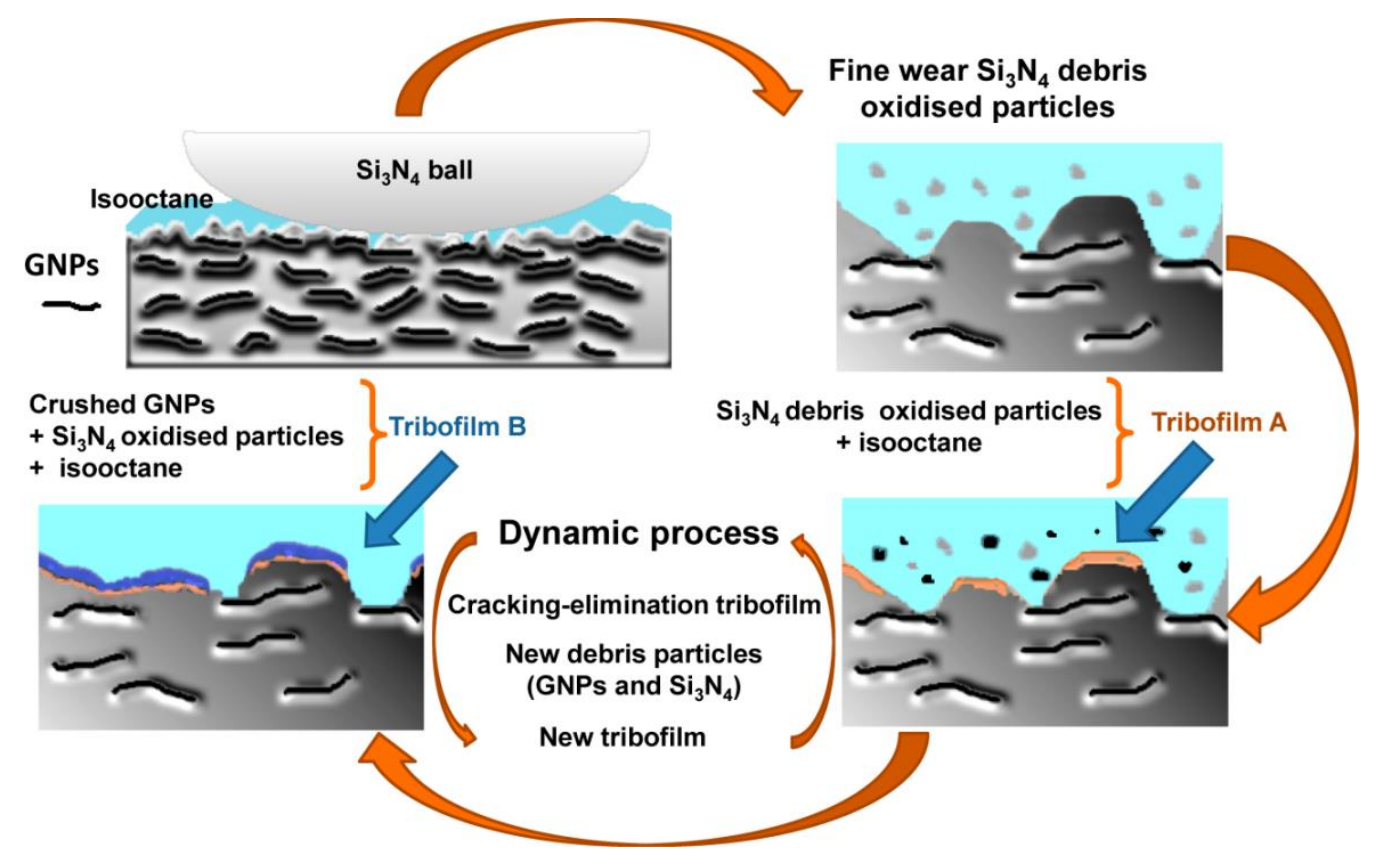

Figure 10. Scheme of the formation and stabilization of the tribolayer in $\mathrm{Si}_{3} \mathrm{~N}_{4} / \mathrm{GNPs}$ composites. 
To summarize, it is important to remark that $\mathrm{Si}_{3} \mathrm{~N}_{4} / \mathrm{GNPs}$ composites exhibited an excellent tribological performance, much better than $\mathrm{Si}_{3} \mathrm{~N}_{4}$ ceramics, promising results that would allow further exploring their potential use for automotive applications, where they could significantly reduce the friction losses, enhance the efficiency of the engine, and enlarge the component durability.

\section{Conclusions}

Laboratory tribological tests under isooctane lubrication evidence an outstanding tribological performance of $\mathrm{Si}_{3} \mathrm{~N}_{4} / \mathrm{GNPs}$ composites as compared to the monolithic material. The friction of composites is about $50 \%$ lower than for the reference ceramics for all tested conditions, and continuously decreases with the GNPs content at intermediate and high loads. All composites are also more wear resistant (up to 63\%) than $\mathrm{Si}_{3} \mathrm{~N}_{4}$, following a monotonically improvement with the amount of fillers at low loads. A self-lubricant carbon-rich tribofilm containing oxidised $\mathrm{Si}_{3} \mathrm{~N}_{4}$ particles is the responsible for the improved friction performance of the composites, protecting against wear as well. The tribofilm augments with the amount of GNPs and counterbalances the negative role played by the decrease of the mechanical properties of the composites in their wear resistance. The instability of the tribofilm produces the loss of its wearprotecting capability.

\section{Acknowledgements}

This work was supported by project MAT2015-67437-R (MICINN, FEDER, UE).

\section{References}

[1] D. Berman, A. Erdemir, A. Sumant, «Graphene: a new emerging lubricant,» Materials Today, vol. 17, nº 1, pp. 31-42, 2014.

[2] O. Penkov, H.-J. Kim, H.-J. Kim, D.-E. Kim, «Tribology of Graphene: A Review,» International Journal of Precision Enegineering and Manufacturing, vol. 15, $\mathrm{n}^{\circ} 3$, pp. 577-585, 2014.

[3] A. Kasar, P. Menezes, «Synthesis and recent advances in tribological applications of graphene,» The International Journal of Advanced Manufacturing Technology, vol. 97, pp. 3999-4019, 2018.

[4] P. Miranzo, M. Belmonte, M. Osendi, «From bulk to cellular structures: A review on ceramic/graphene filler composites,» Journal of the European Ceramic Society, 
vol. 37, pp. 3649-3672, 2017.

[5] P. Rutkowski, L. Stobierski, D. Zientara, L. Jaworska, P. Klimczyk, M. Urbanik, «The influence of the graphene additive on mechanical properties and wear of hotpressed Si3N4 matrix composites,» Journal of the European Ceramic Society, $\mathrm{n}^{\circ}$ 35, pp. 87-94, 2015.

[6] J. Llorente, B. Román-Manso, P. Miranzo, M. Belmonte, «Tribological performance under dry sliding conditions of graphene/silicon carbide composites,» Journal of the European Ceramics Society, vol. 36, nº 3, pp. 429-435, 2016.

[7] C. Balázsi, Z. Fogarasay, O. Tapasztó, A. Kailer, C. Schröder, M. Parchoviansky, D. Galusek, J. Dusza, K. Balázsi, « $\mathrm{Si}_{3} \mathrm{~N}_{4} /$ graphene nanocomposites for tribological application in aqueous environments prepared by attritor miling and hot pressing,» Journal of the European Ceramic Society, vol. 37, n 12, pp. 3797-3804, 2017.

[8] J. Llorente, M. Belmonte, «Friction and wear behaviour of silicon carbide/graphene composites under isooctane lubrication,» Journal of the European Ceramic Society, vol. 38, pp. 3441-3446, 2018.

[9] F. Gutiérrez-Mora, A. Morales-Rodríguez, A. Gallardo-López, R. Poyato, «Tribological behavior of graphene nanoplatelet reinforced 3YTZP composites,» Journal of the European ceramic society, vol. 39, pp. 1381-1388, 2019.

[10] C. Pfister, H. Kubach, U. Spicher, M. Riva, M. Hoffmann, «Use of ceramic sliding systems in a prototype gasoline pump with operating pressures of up to $80 \mathrm{MPa}$,» de .Mechanical properties and perfomance of engineering ceramics an composites VII: ceramic engineering and science proceedings, vol 33., Hoboken, NJ, USA, Wiley \& Sons, Inc., 2012, pp. 101-114.

[11] J. González-Julián, A. Datye, K.-H. Wu, J. Schneider, M. Belmonte, «Robust and wear resistant in-situ carbon nanotube/ $\mathrm{Si}_{3} \mathrm{~N}_{4}$ nanocomposites with a high loading of nanotubes,» Carbon, vol. 72, pp. 338-347, 2014.

[12] C. Pfister, J. Schneider, P. Miranzo, M. Osendi, M. Belmonte, «Carbon nanotubes/silicon nitride nanocomposites for gasoline lubricated high pressure pumps,» Composites Part B: Engineering, vol. 64, pp. 168-174, 2014.

[13] C. Ramírez, F. Figueiredo, P. Miranzo, P. Poza, M. Osendi, «Graphene nanoplatelet/silicon nitride composites with high electrical conductivity,» Carbon, vol. 50, pp. 3607-3615, 2012.

[14] C. Ramírez, L. Garzón, P. Miranzo, M. Osendi, C. Ocal, «Electrical conductivity maps in graphene nanoplatelet/silicon nitride composites using conducting scanning force microscopy,» Carbon, n 49, pp. 3873-3880, 2011. 
[15] ISO. (1997), Geometrical Product Specifications (GPS. Surface texture: profile method. Terms, definitions and surface texture parameters., International Organization for Standarization.

[16] W. Oliver, G. Pharr, «An improved technique for determining hardness and elastic modulus using load and displacement sensing indentation experiments,» Jounal of Materials Research, vol. 7, pp. 1564-1583, 1992.

[17] P. Schreiber, J. Schneider, «Liquid superlubricity obtained for self-mated silicon carbide in nonaqueous low-viscosity fluid,» Tribology International, vol. 134, pp. 7-14, 2019.

[18] S. Hsu, M. Shen, «Wear prediction of ceramics,» Wear, vol. 256, pp. 867-878, 2004.

[19] M. Belmonte, A. Nistal, P. Boutbien, B. Román-Manso, M. Osendi, P. Miranzo, «Toughened and strengthened silicon carbide ceramics by adding graphene-based fillers,» Scripta Materalia, vol. 113, pp. 127-130, 2016.

[20] J. Wang, Y. Cheng, Y. Zhang, Z. Yin, X. Hu, Q. Yuan, «Friction and wear behavior of microwave sintered A12O3/TiC/GPLs ceramic sliding against bearing steel and their cutting performance in dry turning of hardened steel,» Ceramics International, vol. 43, pp. 14827-14835, 2017.

[21] J. Sun, J. Zhao, M. Chen, Y. Zhou, X. Ni, Z. Li, F. Gong, «Multilayer graphene reinforced functionally graded tungsten carbide nano-composites,» Materials and Design, vol. 134, pp. 171-180, 2017.

[22] P. Miranzo, E. García, C. Ramírez, J. González-Julián, M. Belmonte, M. Osendi, «Anisotropic thermal conductivity of silicon nitride ceramics containing carbon nanostructures,» Journal of the European Ceramic Society, vol. 32, pp. 1847-1854, 2012. 